\title{
Laparoscopic Management of Iatrogenic Lesions
}

\author{
Leonardo de Albuquerque Dos Santos Abreu, M.D., ${ }^{1}$ Milton Tanaka, M.D., ${ }^{2}$ Sidney Castro de Abreu, M.D., ${ }^{3}$ \\ Paulo Roberto Kawano, M.D., ${ }^{1}$ Hamilto Yamamoto, M.D., ${ }^{1}$ Rodrigo Arthur Pereira Otsuka, M.D., ${ }^{1}$ \\ Marcelo Rosa Travassos, M.D., ${ }^{1}$ João Luiz Amaro, M.D., ${ }^{1}$ and Oscar Eduardo Fugita, M.D. ${ }^{1}$
}

\begin{abstract}
Purpose: To present our series of patients who underwent laparoscopic correction of iatrogenic lesions and a review of the literature.

Patients and Methods: We evaluated 23 patients who underwent laparoscopic correction of iatrogenic lesions. Thirteen patients had open surgery, 6 had an endoscopic procedure, and 4 had a laparoscopic approach as the first surgical procedure. Vesicovaginal fistulas (VVF) developed in seven patients after open abdominal hysterectomies, and 1 patient presented with a VVF after ureterolithotripsy. A urethral cutaneous fistula developed in one patient after a laparoscopic resection of endometriosis nodules, and 1 patient presented with a ureterovaginal fistula after a perineoplasty. Three patients presented with encrusted ureteral stents after ureterolithotripsy. Ureteral stenosis developed in seven patients: three after open abdominal surgery, three after ureteroscopy, and one after pyeloplasty. One patient had a ureteral injury during laparoscopic partial nephrectomy, and two patients had bowel injuries after a tension-free vaginal tape procedure and a laparoscopic radical prostatectomy.

Results: All patients underwent laparoscopic correction of the iatrogenic injuries. One patient had an early recurrence of a VVF, and one patient had a recurrence of a ureteral stenosis. There was one conversion to open surgery because of technical difficulties and one major bleeding event that necessitated blood transfusion. A lower limb compartmental syndrome developed in one patient.

Conclusion: Despite the small number of patients and different types of surgeries performed, laparoscopic management of iatrogenic lesions seems to be feasible and safe in experienced hands. Its precise role in the management of this stressful condition still needs to be determined.
\end{abstract}

\section{Introduction}

A DVERSE EVENTS occur with some frequency in urologic practice. The complication rates for urologic laparoscopy vary significantly from one series to another, ranging from $3.6 \%$ to $22.1 \%{ }^{1,2}$ The different procedures assessed, different degrees of technical difficulty, and different ways to classify complications may explain such a disparity. ${ }^{3-5} \mathrm{Nev}-$ ertheless, it seems that laparoscopic procedures have complication rates that are comparable to those of open surgeries. $^{6-9}$

In some laparoscopic series, reintervention was necessary in $0.7 \%$ to $1.5 \%$ of the cases, ${ }^{1,10}$ and it was usually associated with technical difficulties, such as adhesions and anatomic structures displacement, particularly when the patient previously had open surgery. Reoperation is always a stressful condition for patients and surgeons, and it carries the spectrum of medical malpractice issues. Malpractice premiums have increased by up to $57 \%$ for urologists in recent years, ${ }^{11}$ and surgical procedures were the greatest generator of claims. $^{11,12}$

Video laparoscopy raised the possibility of minimizing surgical morbidity for a variety of conditions; however, to our knowledge, there are no previous reports that address the role of laparoscopy in the correction of surgical complications. We present our series of patients who underwent laparoscopic correction of iatrogenic lesions and a review of the literature.

${ }^{1}$ Department of Urology, School of Medicine, Universidade Estadual Paulista, Botucatu, Brazil.

${ }^{2}$ Master Clínica, Cascavel, Brazil.

${ }^{3}$ Andros Hospital Urológico de Brasilia, Brasilia, Brazil. 


\section{Patients and Methods}

Twenty-three patients who underwent laparoscopic correction of iatrogenic lesions were evaluated (Table 1). Thirteen patients had open surgery, 6 had an endoscopic procedure, and 4 had a laparoscopic approach as the first surgical procedure.

Vesicovaginal fistula (VVF) developed in seven patients after open abdominal hysterectomy (for benign conditions in five patients and cancer in two patients) and VVF developed in one patient after ureterolithotripsy. All fistulas were located above the bladder trigone. Four of these eight patients had undergone previous surgical attempts to manage the fistula, including endoscopic fulguration of the fistulous tract in one patient, vaginal repair in one patient, and open abdominal repair in two patients.

A ureterocutaneous fistula developed in one patient after endometriotic nodules resection, and an ureterovaginal fistula developed in one patient after perineoplasty. Both patients underwent laparoscopic ureteral reimplantation.

Three patients presented with encrusted ureteral stents secondary to endoscopic management of urinary stones. We were unable to determine the time elapsed from the placement of the ureteral stents to their encrustation because these patients were primarily treated at other institutions. All patients underwent transperitoneal laparoscopic pyelotomy to retrieve the encrusted stent.

Seven patients presented with ureteral strictures after ureterolithotripsy (3), laparoscopic pyeloplasty (1), colon resection for cancer (1), gunshot wound (1), and open hysterectomy (1). Uretero-uretero anastomosis was the only procedure performed in the four first patients. The last two patients needed only ureterolysis while the patient who un- derwent a colon resection underwent ureterolysis and ureteral reimplantation.

One patient with a nonfunctioning upper pole had a ureteral injury during a left partial nephrectomy with transection of the lower pole unit ureter. The injury was promptly recognized and managed with ureteroureterostomy and stent placement.

An enterocutaneous fistula developed in one patient after a laparoscopic radical prostatectomy; the fistula was managed with laparoscopic bowel resection and anastomosis.

During a tension-free vaginal tape procedure for urinary incontinence, one patient had a bowel perforation that was not identified at the time of surgery. Diagnostic laparoscopy was performed to identify and perform primary closure of the bowel perforation.

\section{Results}

All patients underwent laparoscopic correction of the iatrogenic injuries. Two failures $(8.6 \%)$ ensued. One patient had an early recurrence of VVF after removal of the bladder catheter. One patient had an ureteral restenosis after ureteroureterostomy and was lost of follow-up.

We had one conversion (4.3\%) to open surgery during a VVF correction because of intense fibrosis. This patient had had two previous open surgeries: an abdominal hysterectomy for leiomyoma 37 years previously and a simple left nephrectomy for renal exclusion and recurrent urinary tract infection 8 years previously. After an ureteroscopy and placement of a ureteral stent for stones, a VVF developed. This patient is also the only one who needed a blood transfusion.

Table 1. First Surgeries, Surgical Complications, and Laparoscopic Procedures in Patients with Iatrogenic Injuries

\begin{tabular}{|c|c|c|c|}
\hline Patient \# & First surgery & Complication & Laparoscopic procedure \\
\hline 1 & Hysterectomy & VVF & Correction \\
\hline 2 & Hysterectomy & VVF & Correction \\
\hline 3 & Hysterectomy & VVF & Correction \\
\hline 4 & Hysterectomy & VVF & Correction \\
\hline 5 & Hysterectomy & VVF & Correction \\
\hline 6 & Hysterectomy & VVF & Correction \\
\hline 7 & Hysterectomy & VVF & Correction \\
\hline 8 & Ureterolithotripsy & VVF & Correction (conversion) \\
\hline 9 & $\begin{array}{l}\text { Laparoscopic } \\
\text { Endometriotic nodules resection }\end{array}$ & Ureterocutaneous fistula & Ureteral reimplantation \\
\hline 10 & Perineoplasty & Ureterovaginal fistula & Ureteral reimplantation \\
\hline 11 & Ureterolithotripsy & Encrusted ureteral stent & Pyelotomy and stent removal \\
\hline 12 & Ureterolithotripsy & Encrusted ureteral stent & Pyelotomy and stent removal \\
\hline 13 & Open pyelolithotomy & Encrusted ureteral stent & Pyelotomy and stent removal \\
\hline 14 & Ureterolithotripsy & Ureteral stenosis & Ureteroureterostomy \\
\hline 15 & Ureterolithotripsy & Ureteral stenosis & Ureteroureterostomy \\
\hline 16 & Ureterolithotripsy & Ureteral stenosis & Ureteroureterostomy \\
\hline 17 & Laparoscopic pyeloplasty & Ureteral stenosis & Ureteroureterostomy \\
\hline 18 & Colon resection & Ureteral stenosis & Ureterolysis and reimplantation \\
\hline 19 & GSW & Ureteral stenosis & Ureterolysis \\
\hline 20 & Hysterectomy & Ureteral stenosis & Ureterolysis \\
\hline 21 & Laparoscopic partial nephrectomy & Ureteral injury & Ureteroureterostomy \\
\hline 22 & Laparoscopic radical prostatectomy & Enterocutaneous fistula & Bowel resection and anastomosis \\
\hline 23 & TVT & Bowel perforation & Primary closure \\
\hline
\end{tabular}

$\mathrm{VVF}=$ vesicovaginal fistula; GSW = gunshot wound; TVT $=$ tension-free vaginal tape. 
In another patient who underwent a VVF correction, a lower limb compartmental syndrome developed that was associated with deep vein thrombosis (DVT). Risk factors for DVT in this patient were the prolonged operative time (390 minutes), body mass index (30), hypothyroidism, and the lithotomy position for an associated pubovaginal sling for urinary stress incontinence.

\section{Discussion}

The widespread use of the laparoscopic approach in urology has led to increasingly liberal grounds for indication of this operative technique. More and more open surgical procedures have been in competition with or even superseded by their laparoscopic counterpart. There is some concern, however, about laparoscopic management of iatrogenic lesions. Extensive previous abdominal or pelvic surgery and pelvic fibrosis are considered relative contraindications to laparoscopic surgery. ${ }^{13}$

Abdominal hysterectomy remains the most common cause of VVF, occurring in 1/1800 hysterectomies ${ }^{14}$ and accounting for about $85 \%$ of cases; radiation $(10 \%)$ and obstetric injury $(5 \%)$ are the other major causes. ${ }^{15}$ In terms of the best surgical approach, the arguments continue as to whether the abdominal or the vaginal route is better for VVF repair. So far, there are no significant statistical data to answer which one is better.

The vaginal approach seems to be easy, safe, and quicker for most early simple fistulas, ${ }^{16}$ while the abdominal approach may be indicated to address supratrigonal VVFs ${ }^{17}$ or more complex fistulas, such as those that result from radiation therapy with small capacity bladders. ${ }^{18}$ Although the surgical results are mainly related to the cause of the fistula and the experience of the surgeon, failure rates range from $4 \%$ to $37 \%$, according to the surgical approach: open abdominal or vaginal techniques. ${ }^{19}$

The laparoscopic repair of a VVF may offer the patient the advantages of a shorter hospital stay, more rapid postoperative recovery, and better cosmetic results than the traditional abdominal approach. Laparoscopy also allows excellent magnification and exposure of the pelvic structures, providing fast and direct access to the fistula and avoiding anterior cystotomy or bipartition of the bladder, as in the $\mathrm{O}^{\prime}$ Connor procedure. ${ }^{17}$ It also allows resection of the fistulous tract.

Failure rates range from $0 \%$ to $8 \%$ for the laparoscopic approach. ${ }^{20-22}$ In our series, four of eight (50\%) patients had previously undergone unsuccessful open surgery to correct the VVF; this made fistulous tract recognition more difficult because of excessive tissue scarring. We had one conversion $(11 \%)$ and one failure $(12.5 \%)$ in the laparoscopic repair of VVF. Laparoscopic freehand intracorporeal suturing, particularly in the pelvis, can be cumbersome, and continuous training and practice are mandatory to perform this type of surgery.

Injury to the ureter is a potential complication of any difficult abdominopelvic surgical procedure, whether gynecologic, obstetric, general surgical, or urologic. The incidence varies between $0.5 \%$ and $10 \%$ in most series. ${ }^{23,24}$ Gynecologic surgery has been the traditional cause of more than $50 \%$ of iatrogenic ureteral injuries, followed by general surgical procedures..$^{25-27}$ In the last 10 to 15 years, however, with the increase in complex minimally invasive endoscopic proce- dures, such as ureteroscopy, ureterolithotripsy, and endopyelotomy, urologic procedures now account for most incidences of ureteral injuries. ${ }^{28-32}$

Most of the urologic ureteral injuries are identified intraoperatively and are corrected promptly. ${ }^{29}$ Management of ureteral injuries can be accomplished by several endoscopic techniques, such as balloon dilation and endoureterotomy. Results vary, however, according to the stricture cause, location, and length, and renal function.

Late detected injuries necessitate more procedures to repair the ureter and have worse results. ${ }^{25,29,33,34}$ Overall success rates range from $48 \%$ to $88 \%$ for balloon dilation, $55 \%$ to $85 \%$ for endoureterotomy, and $91 \%$ to $97 \%$ for conventional open surgery. ${ }^{35}$ In our series of 10 patients, laparoscopic management of early (6) and late (4) detected ureteral injuries was accomplished in all cases but one (success rate, $90 \%$ ) despite the fact that it was a uretero-uretero anastomosis, ureterolysis, or ureteral reimplantation.

Encrustation, one of the most serious complications of ureteral stents, is well documented in the literature. ${ }^{36-42}$ Mean time from insertion of the ureteral stent to encrustation is about 6 months. Known risk factors for stent encrustation are long indwelling time, urinary sepsis, history of or concurrent stone disease, chemotherapy, pregnancy, chronic renal failure, and metabolic or congenital abnormalities. ${ }^{38-41}$

Management of encrusted stents may necessitate multiple approaches. First-line options are extracorporeal shockwave lithotripsy (SWL), ureteroscopy, and percutaneous nephrolithotomy; however, frequently more than one procedure is needed. The amount of encrustation is another factor that influences the therapeutic approach. ${ }^{43}$

Laparoscopy emerges as a minimally invasive option to manage stent encrustation. Bhansali and associates ${ }^{44}$ described laparoscopic management of a heavily encrusted ureteral stent. In our series, we managed three cases of heavily encrusted stents with laparoscopic pyelotomy, after repeated failure of SWL.

Bowel injuries during minimally invasive procedures may be difficult to diagnose. Signs and symptoms may not be readily recognized in some cases. Laparoscopy may provide early diagnosis and management when bowel injury is suspected. ${ }^{45}$ Late recognized injuries can also be managed laparoscopicaly. ${ }^{46}$ Our two patients received an early diagnosis and were treated by the laparoscopic approach.

Improvements in video technology, endoscopic instruments, and laparoscopic skills, particularly intracorporeal suturing, have allowed surgeons to expand their repertoire of minimally invasive procedures. This minimal access approach has the potential to minimize postoperative pain, shorten hospital stay, and speed convalescence. Compared with other types of minimally invasive procedures, laparoscopy has the advantage of reproducing the open technique.

Despite of the small number of patients and different types of surgeries performed, laparoscopic management of iatrogenic lesions seems to be feasible and safe in experienced hands. Its precise role in the management of this stressful condition still needs to be determined.

\section{References}

1. Vallancien G, Cathelineau X, Baumert H, Doublet JD, Guillonneau B. Complications of transperitoneal laparoscopic 
surgery in urology: Review of 1,311 procedures at a single center. J Urol 2002;168:23-26.

2. Permpongkosol S, Link RE, Su LM, Romero FR, Bagga HS, Pavlovich CP, Jarrett TW, Kavoussi LR. Complications of 2,775 urological laparoscopic procedures: 1993 to 2005. J Urol 2007;177:580-585.

3. Clavien PA, Sanabria JR, Strasberg SM. Proposed classification of complications of surgery with examples of utility in cholecystectomy. Surgery 1992;111:518-526.

4. Dindo D, Demartines N, Clavien PA. Classification of surgical complications: A new proposal with evaluation in a cohort of 6336 patients and results of a survey. Ann Surg 2004;240:205-213.

5. Guillonneau B, Abbou CC, Doublet JD, Gaston R, Janetschek G, Mandressi A, Rassweiler JJ, Vallancien G. Proposal for a "European Scoring System for Laparoscopic Operations in Urology". Eur Urol 2001;40:2-7.

6. Kavoussi LR, Sosa E, Chandhoke P, et al. Complications of laparoscopic pelvic lymph node dissection. J Urol 1993; 149:322-325.

7. Gill IS, Kavoussi LR, Clayman RV, et al. Complications of laparoscopic nephrectomy in 185 patients: A multi-institutional review. J Urol 1995;154:479-483.

8. Rassweiler J, Fornara $\mathrm{P}$, Weber $\mathrm{M}$, et al. Laparoscopic nephrectomy: The experience of the laparoscopic working group of the German Urological Association. J Urol 1998;160: $18-21$.

9. Brunt LM, Doherty GM, Norton JA, Soper NJ, Quasebarth MA, Moley JF. Laparoscopic adrenalectomy compared to open adrenalectomy for benign adrenal neoplasms. J Am Coll Surg 1996;183:1-10.

10. Parsons JK, Varkarakis I, Rha KH, Jarrett TW, Pinto PA, Kavoussi LR. Complications of abdominal urologic laparoscopy: Longitudinal five-year analysis. Urology 2004;63: 27-32.

11. Sobel DL, Loughlin KR, Coogan CL. Medical malpractice liability in clinical urology: A survey of practicing urologists. J Urol 2006;175:1847-1851.

12. Perrotti M, Badger W, Prader S, Moran ME. Medical malpractice in urology, 1985 to 2004: 469 consecutive cases closed with indemnity payment. J Urol 2006;176:21542157.

13. Gill IS, Kerbl K, Meraney AM, et al. Basics of laparoscopic urologic surgery. In: Walsh PC, Retik AB, Vaughan ED, Wein AJ, Kavoussi LR, Novick AC, Partin AW, Peters CA, eds. Campbell's Urology. Philadelphia: WB Saunders, 2002, pp 3457-3458.

14. Miller EA, Webster GD. Current management of vesicovaginal fistulae. Curr Opin Urol 2001;11:417-421.

15. Symmonds RE. Incontinence: Vesical and urethral fistulas. Clin Obstet Gynecol 1984;27:499-514.

16. Goodwin WE, Scardino PT. Vesicovaginal and ureterovaginal fistulas: A summary of 25 years of experience. J Urol 1980;123:370-374.

17. O'Conor VJ Jr, Sokol JK, Bulkley GJ, Nanninga JB. Suprapubic closure of vesicovaginal fistula. J Urol 1973;109:51-54.

18. Blaivas JG, Heritz DM, Romanzi LJ. Early versus late repair of vesicovaginal fistulas: Vaginal and abdominal approaches. J Urol 1995;153:1110-1113.

19. Nesrallah LJ, Srougi M, Gittes RF. The O'Connor technique: The gold standard for supratrigonal vesicovaginal fistula repair. J Urol 1999;161:566-568.

20. Sotelo R, Mariano MB, García-Segui A, et al. Laparoscopic repair of vesicovaginal fistula. J Urol 2005;173:1615-1618.
21. Chibber PJ, Shah HN, Jain P. Laparoscopic O'Conor's repair for vesico-vaginal and vesico-uterine fistulae. BJU Int 2005;96:183-186.

22. Nagraj HK, Kishore TA, Nagalaksmi S. Early laparoscopic repair for supratrigonal vesicovaginal fistula. Int Urogynec J Pelvic Floor Dysfunct 2007;18:759-762.

23. Bright TC III, Peters PC. Ureteral injuries secondary to operative procedures: Report of 24 cases. Urology 1977;9: 22-26.

24. Neuman M, Eidelman A, Langer R, Golan A, Bukovsky I, Caspi E. Iatrogenic injuries to the ureter during gynecologic and obstetric operations: Surg Gynecol Obstet 1991;173: 268-272.

25. Flynn JT, Tiptaft RC, Woodhouse CR, Paris AM, Blandy JP. The early and aggressive repair of iatrogenic ureteric injuries. Br J Urol 1979;51:454-457.

26. Hughes ES, McDermott FT, Polglase AL, Johnson WR. Ureteric damage in surgery for cancer of the large bowel. Dis Colon Rectum 1984;27:293-295.

27. Dowling RA, Corriere JN Jr, Sandler CM. Iatrogenic ureteral injury. J Urol 1986;135:912-915.

28. Assimos DG, Patterson LC, Taylor CL. Changing incidence and etiology of iatrogenic ureteral injuries. J Urol 1994; 152:2240-2246.

29. Selzman AA, Spirnak JP. Iatrogenic ureteral injuries: A 20year experience in treating 165 injuries. J Urol 1996;155: 878-881.

30. Stoller ML, Wolf JS Jr. Endoscopic ureteral injuries. In: McAninch JW, ed. Traumatic and Reconstructive Urology. Philadelphia: WB Saunders Co, 1996, 199-212.

31. Preston JM. Iatrogenic ureteric injury: Common medicolegal pitfalls. BJU Int 2000;86:313-317.

32. Meng MV, Freise CE, Stoller ML. Expanded experience with laparoscopic nephrectomy and autotransplantation for severe ureteral injury. J Urol 2003;169:1363-1367.

33. Blandy JP, Badenoch DF, Fowler CG, Jenkins BJ, Thomas NW. Early repair of iatrogenic injury to the ureter or bladder after gynecological surgery. J Urol 1991;146: 761-765.

34. Al-Awadi K, Kehinde EO, Al-Hunayan A, Al-Khayat A. Iatrogenic ureteric injuries: Incidence, aetiological factors and the effect of early management on subsequent outcome. Int Urol Nephrol 2005;37:235-241.

35. Hafez KS, Wolf JS Jr. Update on minimally invasive management of ureteral strictures. J Endourol 2003;17:453-464.

36. Mohan-Pillai K, Keeley FX Jr, Moosa SA, Smith G, Tolley DA. Endourological management of severely encrusted ureteral stents. J Endourol 1999;13:377-379.

37. Borboroglu PG, Kane CJ. Current management of severely encrusted ureteral stents with a large associated stone burden. J Urol 2000;164:648-650.

38. Monga M, Klein E, Castañeda-Zúñiga WR, Thomas R. The forgotten indwelling ureteral stent: A urological dilemma. J Urol 1995;153:1817-1819.

39. Singh I, Gupta NP, Hemal AK, Aron M, Seth A, Dogra PN. Severely encrusted polyurethane ureteral stents: Management and analysis of potential risk factors. Urology 2001;58:526-531.

40. Schulze KA, Wettlaufer JN, Oldani G. Encrustation and stone formation: Complication of indwelling ureteral stents. Urology 1985;25:616-619.

41. Spirnak JP, Resnick MI. Stone formation as a complication of indwelling ureteral stents: A report of 5 cases. J Urol 1985; 134:349-351. 
42. Somers WJ. Management of forgotten or retained indwelling ureteral stents. Urology 1996;47:431-435.

43. Lam JS, Gupta M. Tips and tricks for the management of retained ureteral stents. J Endourol 2002;16:733-741.

44. Bhansali M, Patankar S, Dobhada S. Laparoscopic management of a retained heavily encrusted ureteral stent. Int J Urol 2006;13:1141-1143.

45. Hansen AJ, Tessier DJ, Anderson ML, Schlinkert RT. Laparoscopic repair of colonoscopic perforations: Indications and guidelines. J Gastrointest Surg 2007;11:655-659.

46. Sotelo R, Garcia A, Yaime H, Rodríguez E, Dubois R, Andrade RD, Carmona O, Finelli A. Laparoscopic rectovesical fistula repair. J Endourol 2005;19:603-607.

47. Sotelo R, Mirandolino M, Trujillo G, et al. Laparoscopic repair of rectourethral fistulas after prostate surgery. Urology 2007;70:515-518.
Address reprint requests to: Oscar Eduardo Fugita, M.D. Faculdade de Medicina de Botucatu Departamento de Urologia - UNESP Dist. De Rubião Jr S/N Botucatu, São Paulo, Brazil CEP 18618970

E-mail: fugita@fmb.unesp.br

\begin{tabular}{|c|}
\multicolumn{1}{c|}{ Abbreviations Used } \\
DVT $=$ deep vein thrombosis \\
SWL $=$ shockwave lithotripsy \\
VVF $=$ vesicovaginal fistula
\end{tabular}


